\title{
The Impact of Online Teaching Under the COVID-19 Pandemic on the Teaching of Medical Immunology and Medical Microbiology to Second-Year Dentistry Students: A Prospective Comparative Study
}

\section{Xiaoqian Zhang ( $\nabla$ janet8897486@163.com )}

Haiyuan College of Kunming Medical University

Yuwei Jiang

Haiyuan College of Kunming Medical University

\section{Yihan Chen}

Haiyuan College of Kunming Medical University

\section{Bishu Ma}

Haiyuan College of Kunming Medical University

\section{Zhen Li}

Haiyuan College of Kunming Medical University

\section{Yunjiao Zhang}

Haiyuan College of Kunming Medical University

\section{Dan Liu}

Zhuhai College of Science and Technology

Jia Luo

Chinese Academy of Medical Sciences and Peking Union Medical College

Hui Zhang

Haiyuan College of Kunming Medical University

\section{Research Article}

Keywords: Online teaching, Medical students, COVID-19, Medical microbiology, Medical immunology

Posted Date: February 21st, 2022

DOI: https://doi.org/10.21203/rs.3.rs-1371495/v1

License: (c) (i) This work is licensed under a Creative Commons Attribution 4.0 International License. Read Full License 


\section{Abstract \\ Background}

Medical microbiology and medical immunology are required introductory courses for second-year dentistry students. It is essential to find suitable teaching methods after the outbreak of COVID-19 to implement the call for "stop class, but not stop teaching and not stop learning."

\section{Methods}

We mainly used Rain Classroom for online teaching and QQ Group Classroom to support education during this particular period.

\section{Result}

We assessed the effectiveness of this special period instruction by analyzing anonymous questionnaires and final exam results. The anonymous questionnaire showed that most of the students were satisfied with this online instruction and found it very helpful in answering their questions and solving their problems. The final exam results showed that teaching in 2020 was no worse than teaching in 2019 and better in terms of pass rate. Teaching in 2021 was worse than in 2020, but there was a breakthrough in the highest score.

\section{Conclusion}

These data suggest that online teaching during the epidemic had an impact on teaching effectiveness. Most students are satisfied with online teaching, but some students' grades are affected, which may be related to the fact that some students were not comfortable with blended teaching or online teaching. We share our experiences and reflections on online and blended teaching of medical immunology and medical microbiology courses during the epidemic, hoping that it will be helpful for other teachers to teach.

\section{Background}

In January 2020, the coronavirus disease 2019 (COVID-19) in China entered a dramatic outbreak[1], on January 27, 2020, the Chinese Ministry of Education issued a notice of postponement of the start of the 2020 spring semester, and on February 5, 2020, the Ministry of Education put forward " stop class, but not stop teaching and not stop learning."To fully implement this call notice, Haiyuan College of Kunming Medical University promptly called on teachers to change the traditional offline teaching to online teaching to ensure the advancement of the regular teaching schedule. The ability to truly implement this method is due to the rapid development of the Internet, which gives students more ways and 
opportunities to learn online, and online teaching compared to traditional teaching models, first it reduces costs and improves learning efficiency[2]; second it has flexibility in terms of time and location [3]; third it is effective in increasing learner engagement and enriching opportunities for learners to acquire and apply knowledge [4]; fourth it facilitates for specific professions that require lifelong learning, such as medical classes. The demand of the online teaching market has been accompanied by the emergence of more and more online teaching software such as MOOC, XuetangX, icourses, etc.

Both medical immunology and medical microbiology are essential basic subjects for future professional courses for dentistry students. Therefore, we choose to offer these two courses for students in the second semester of their second year of college when they already have some other basic knowledge. Immune function and immune dysfunction are very complex basic scientific concepts [5]囚and medical microbiology are also abstract,it is a great challenge for students to learn these two courses at home during the novel coronavirus pneumonia epidemic by themselves with only online learning, because of the large number of knowledge points and high learning pressure. We are also thinking about effective educational strategies that medical schools should implement to improve primary education[6].At the beginning of the Medical Immunology and Medical Microbiology courses in 2020, we conducted online teaching of the teaching tools Rain Classroom and QQ Group Classroom, a new intelligent toolbox for live online teaching developed jointly by Tsinghua University and Xuetang Company in China, for second-year undergraduate students of dentistry at Haiyuan College of Kunming Medical University (Class of 2018), QQ group classroom is an online classroom model based on the establishment of QQ groups. On June 8, 2020, after students return to campus, we still use the online teaching model to give students a final review and finally an offline exam. To evaluate the effectiveness of teaching medical immunology and medical microbiology during the COVID-19 outbreak, we administered an anonymous questionnaire to students at the end of the course. Also, we compared the medical immunology and medical microbiology final grades of dentistry students in 2019 (class of 2017), 2020 (class of 2018), and 2021 (class of 2019), before the outbreak the study was conducted to evaluate better the impact of online teaching on the teaching of medical immunology and medical microbiology during the novel coronavirus pneumonia epidemic and to gain experience in education during particular periods, which will help us to reform student-centered teaching.

\section{Methods}

\section{Design of online teaching}

In our school, we mainly use the rain classroom to teach medical immunology and medical microbiology using the pre-class,in-class, post-class lecture mode. Pre-class preparation: first, the teacher establishes the class and students join the class by real names to build a simulated off-line teaching classroom. Then, teachers can carry out multi-module online teaching before, during and after class. Before class, teachers distribute pre-course materials and post relevant pre-course exercises and keep track of students' answers for more accurate lesson preparation. In the middle of the lesson, teachers can teach live via Rain Classroom or distribute the courseware for students to study independently. During the live 
lecture, teachers can send questions to grasp the real-time learning situation of students. They can also randomly check students' mastery through "random questions" during the lesson. Students can also send pop-ups and messages to achieve timely feedback on questions, which improves students' learning efficiency and enhances teacher-student interaction. After the lesson, teachers can distribute exercises and tests related to the content of the lesson, so that students can use them to consolidate their knowledge and fill in the gaps. In addition, we set up a QQ group (a popular social media platform in China) to facilitate students to ask questions and teachers to answer them promptly, and they all use the same syllabus and credit hours.

\section{Comparison of final grades}

We compared the final grades of the dentistry students in the class of 2017 who used the traditional teaching mode before the epidemic, the dentistry students in 2018 who used the online teaching mode at the time of the epidemic, and the dentistry students in the class of 2019 who used the blended teaching mode after they could return to school usually.

\section{Questionnaire survey}

We recruited 252 second-year dentistry students (class of 2018) studying medical immunology and medical microbiology at Haiyuan College of Kunming Medical University to participate in the questionnaire study. Because they were affected by the epidemic and completed the whole course with rain classroom and so on, they had the complete knowledge and comparison of online teaching. First, medical immunology and medical microbiology were taught by the Medical Microbiology and Immunology Department of the Department of Basic Teaching at our school.At the end of the course, we administered an anonymous 5-point Likert scale questionnaire to the dentistry students of the class of 2018, with questionnaire scores ranging from 1 (not at all satisfied) to 5 (completely satisfied). For the above questionnaire, the original English items were translated into Chinese and then back-translated to confirm the consistency between the original and provided items, as we provided them in Chinese. Questionnaire: Was the online teaching helpful to you in reviewing your knowledge after class? ; To what extent was online instruction helpful to you in answering questions and solving problems? Did online teaching help you to master your knowledge better? Does online teaching help you to study efficiently? How satisfied were you with the online teaching during the novel coronavirus pneumonia epidemic?

\section{Result}

Data are expressed as mean \pm SEM. final exam scores of undergraduate students from the classes of 2019, 2018 and 2017 were subjected to Kruskal-Wallis test. P-value less than 0.05 was considered statistically significant. Our data analyses were performed using SPSS26.0. 


\section{Analysis of the questionnaire}

At the end of the course, an anonymous questionnaire was administered to the 2018 class of dentistry students, with 252 students participating in the questionnaire. The questionnaire showed that $59.2 \%$ of the students were satisfied with the online teaching during the epidemic (Figure $1(\mathrm{e})$ ), $61.9 \%$ of the students thought that the online teaching helped review the knowledge points (Figure 1(a)), $62.55 \%$ of the students thought that the online teaching could help them answer their questions and solve their problems (Figure 1 (c)), and $39.57 \%$ of the students thought that online teaching has no way to learn efficiently (Figure $1(\mathrm{~d})$ ), and $54.76 \%$ of students think that online teaching can help them improve their mastery of knowledge (Figure 1(b)). This reflects that students as a whole were satisfied with the use of online teaching during the epidemic, and believed that online teaching contributed to their ability to answer questions, review points, and improve their mastery of knowledge .Still, they were not able to study more efficiently in the online teaching environment.

\section{Comparison of final grades}

Table 1. The section analysis of final examination scores in medical immunology.

\begin{tabular}{|llllll|}
\hline & Excellence & Good & Medium & Poor & Failure \\
\hline Score & A (85-100) & B (80-84) & C (70-79) & D (60-69) & E $(0-59)$ \\
\hline 2019 grade & $5 \%$ & $12 \%$ & $35 \%$ & 35 & $13 \%$ \\
\hline 2018 grade & $6 \%$ & $12 \%$ & $43 \%$ & $33 \%$ & $6 \%$ \\
\hline 2017 grade & $12 \%$ & $14 \%$ & $31 \%$ & $35 \%$ & $8 \%$ \\
\hline & Average score & Pass rate & SEM & Highest score & Lowest score \\
\hline 2019 grade & 70.10 & $87.3 \%$ & 0.538 & 96 & 36 \\
\hline 2018 grade & 72.18 & $94.3 \%$ & 0.478 & 92 & 60 \\
\hline 2017 grade & 71.95 & $92.3 \%$ & 0.672 & 99 & 35 \\
\hline
\end{tabular}

Table 2. The section analysis of final examination scores in medical microbiology. 


\begin{tabular}{|llllll|}
\hline & Excellence & Good & Medium & Poor & Failure \\
\hline Score & A (85-100) & B (80-84) & C (70-79) & D (60-69) & E (0-59) \\
\hline 2019 grade & $15 \%$ & $13 \%$ & $41 \%$ & $14 \%$ & $4 \%$ \\
\hline 2018 grade & $15 \%$ & $24 \%$ & $48 \%$ & $14 \%$ & $0 \%$ \\
\hline 2017 grade & $36 \%$ & $16 \%$ & $30 \%$ & $14 \%$ & $4 \%$ \\
\hline & Average score & Pass rate & SEM & Highest score & Lowest score \\
\hline 2019 grade & 73.49 & $93.0 \%$ & 0.584 & 96 & 41 \\
\hline 2018 grade & 77.08 & $100 \%$ & 0.438 & 90 & 52 \\
\hline 2017 grade & 79.48 & $96.2 \%$ & 0.737 & 94 & 46 \\
\hline
\end{tabular}

To assess the effectiveness of online teaching in particular periods, we evaluated the final grades of medical microbiology and medical immunology for dentistry students of the same course syllabus, class hours, and teachers taught in 2018, 2019 and 2017. Two hundred thirty-four students took the final exam in the class of 2017, and the average score of medical immunology: $71.95 \pm 0.672$; the average score of medical microbiology. $79.48 \pm 0.737 ; 249$ students took the final exam in the class of 2018 , and the average score of Medical Immunology: $72.18 \pm 0.478$; the average score of Medical Microbiology: $77.08 \pm$ $0.438 ; 315$ students took the final exam in the class of 2019, and the average score of Medical Immunology: $70.10 \pm 0.538$; the average score of Medical Microbiology. 73.49 \pm 0.584 ; from the average scores of the three grades (Table 1)(Table 2). The average score of medical immunology in class 2018 is $72.18 \pm 0.478$, which is the highest among the three grades, and the average score of medical microbiology in class 2017 is $79.48 \pm 0.737$, which is the highest among the three grades, so for medical immunology adopting online teaching mode can help students better understand and master the knowledge points, while for medical microbiology, the traditional teaching model may help students better understand and master the knowledge points. In the homogeneity test of variances for the three grades, $p=0.000<0.05$ (Figure 2), so ANOVA could not be used for comparison, and we used the KruskalWallis test to obtain $p=0.023<0.05$ (Figure 2 ) for the final grade of medical immunology and $p=0.000<0.05$ (Figure 2) for the final grade of medical microbiology. So the final grades of medical immunology and medical microbiology in the three grades are statistically significantly different, which indicates that the change of teaching mode is changing the effect of teaching. 2018 class was taught entirely by online teaching mode, and the passing rate of final grades ( $94 \%$ and $100 \%)$ in the two courses in the three grades (Table 1)(Table 2) were both the highest, indicating that online instruction has some facilitative effect in taking care of every student's learning. After the resumption of offline teaching, drawing on the teaching experience of the special period and adopting a hybrid online and offline teaching, the final grade pass rate (87\% and $93 \%$ ) of both courses (Table 1)(Table 2) of the class of 2019 is the lowest among the three grades, which is lower than that of both the classes of 2017 and 2018, indicating that some students are not yet well adapted to the hybrid teaching model. the class of 2017 adopts the traditional teaching model for offline teaching, the final grade excellence rates (12\% and 36\%) 
for both courses (Table 1)(Table 2) were the highest among the three grades, indicating that students were able to master their knowledge better under traditional teaching. These data suggest that online instruction during the epidemic impacted on teaching effectiveness, with the positive impact outweighing the negative impact.

\section{Discussion}

This outbreak of COVID-19 has dramatically boosted the use of online teaching in Chinese universities. Although our university has resumed classroom teaching, we are unsure how long the coronavirus crisis will last, and the teaching model needs further improvement. Experts warn that the impact of this COVID19 will reverberate in higher education worldwide for a more extended. Universities should prepare different ways to deal with coronavirus in advance with the help of teaching experience in spring semester 2020 to maintain normal teaching procedures. By analyzing the final results, we concluded that online teaching could provide students with a more vivid understanding of the immune mechanisms for medical immunology. For medical microbiology, online teaching may not promote student performance, also indicating that there may be differences between subjects and teaching programs need to be developed according to the characteristics of the subject. Under traditional teaching, the higher rate of student achievement (Table 1) (Table 2) may be related to the fact that students are more familiar with the traditional offline teaching. The higher pass rate (Table 1)(Table 2)in the online teaching environment may be related to the advantages of online teachings, such as the convenience of answering questions. 2019 grade students are taught in a blended model, a hybrid learning model that combines online teaching and face-to-face classroom teaching. Comprehensive understanding and learning knowledge[7]》 but the students' final grade pass rate is lower than that of classmates in 2017 and 2019 . Still, the highest score is higher than that of classmates in 2017 and 2018 (Table 1 and 2 ), probably because some students do not have the means to adapt to this teaching model fully, or there may be problems with the design of our teaching model, which has implications for our next This provides a direction for the next student-centered teaching and learning reform in our school. Through an anonymous questionnaire, we learned that students do not think there is a way to teach efficiently online (Figure 1(d)). Samiullah Dost et al. showed that the effectiveness of online teaching might be interfered with by the external environment because the presence of factors such as home learning, students may have network problems and other factors that interfere with students' learning can affect the effectiveness of students' online learning [8] \but online teaching can still be a significant contributor to the future of teaching and learning in the medical profession.

In the past study, Luo $Y$ et al. argued that online teaching helped them to master their knowledge more flexibly. They could master what they wanted to master after watching some videos, completing some exercises, or participating in the discussion of the course online[9] $₫$ not only limited to the single mode of teaching in school. And for healthcare workers to fill their knowledge and recognize knowledge errors, remain competitive, and ensure patient health, it is necessary to engage in a lifelong learning approach to fulfill their duties $[4,10]$ \and online learning as an emerging teaching method increase the accessibility and flexibility of their continuing education and flexibility [11] هso online teaching as a teaching method 
can be used more often for complementary medical education in the future. After the new crown epidemic made the traditional teaching mode unworkable, we suggested that online teaching could replace the traditional offline teaching method in the future. However, it has also been pointed out that online learning complements to their offline learning content rather than an alternative to traditional teaching[12].Francis et al. suggest that the different attitudes towards online teaching may be related to each individual's personality traits [13]. Thus, we also analyzed the satisfaction of teaching online basic medical courses. The results of the questionnaire showed that students' satisfaction with online lectures was high during the novel coronavirus epidemic.

Therefore, to respond to the call of the Chinese Ministry of Education to "Stop class, but not stop teaching and not stop learning" during the novel coronavirus epidemic, Chinese medical schools can adopt different online teaching methods to enable students to absorb the knowledge better. In the future, we can also use online teaching to improve the efficiency of teachers and students in basic medical education.

Ideally,this would be a randomized pilot study. Still, we cannot rule out the possibility of confounding at this point, as students may have exchanged information themselves about the questionnaire, resulting in the current selection. Also, because this questionnaire was limited to Chinese medical students, we did not investigate cultural differences. Finally, Rain Classroom online is a long-term teaching software.Our study was limited to online teaching during the epidemic, so there were limitations to the duration of our questionnaire study.

\section{Conclusion}

We assessed the effectiveness of this special period instruction by analyzing anonymous questionnaires and final exam results. The anonymous questionnaire showed that most of the students were satisfied with this online instruction and found it very helpful in answering their questions and solving their problems. The final exam results showed that teaching in 2020 was no worse than teaching in 2019 and better in terms of pass rate. Teaching in 2021 was worse than in 2020, but there was a breakthrough in the highest score. These data suggest that online teaching during the epidemic had an impact on teaching effectiveness. Most students are satisfied with online teaching, but some students' grades are affected, which may be related to the fact that some students were not comfortable with blended teaching or online teaching. In response to feedback on student performance, we will also adjust the teaching mode of our medical immunology and medical microbiology courses. Here, we share our practices and reflections on teaching medical immunology and medical microbiology during the novel coronavirus pneumonia epidemic in the hoping that they will be useful to other teachers who are teaching practitioners.

\section{Abbreviations}

COVID-19

the coronavirus disease 2019 
MOOC

Massive Open Online Course.

\section{Declarations}

\section{Ethics approval and consent to participate}

This article does not contain any studies with human participants or animals performed by any of the authors.

\section{Consent for publication}

Not applicable.

\section{Availability of data and material}

All data generated or analysed during this study are included in this article.

\section{Competing interests}

The authors declare that they have no competing interests.

\section{Funding}

Not applicable.

\section{Authors' contributions}

B. M., Y. J., Z. L., Y. Z., D. L., J. L., and H. Z.; Data provision, X. Z., Y. J., and Y.C.; Data curation, X. Z.; Formal analysis, X. Z.; Methodology, X. Z. and Y. J.; Project administration, X. Z.; Software, X. Z.; Supervision, X. Z. and Y. J.; Validation, X. Z. and Y.C.; Visualization, X. Z.; Writing-original draft, X. Z. and Y. J.; Writingreview \& editing, X. Z. and Y. J. contributed equally to this work and should be consider as co-first authors.

\section{Acknowledgements}

The authors received no specific funding for this work. 


\section{References}

1. Zhu N, Zhang D, Wang W, Li X, Yang B, Song J, Zhao X, Huang B, Shi W, Lu R, Niu P, Zhan F, Ma X, Wang D, Xu W, Wu G, Gao GF, Tan W. A Novel Coronavirus from Patients with Pneumonia in China, 2019. N Engl J Med. 2020;382:727-33.

2. Memon AR, Rathore FA. Moodle and Online Learning in Pakistani Medical Universities: An opportunity worth exploring in higher education and research. J Pak Med Assoc. 2018;68:1076-8.

3. Robinson R. Delivering a medical school elective with massive open online course (MOOC) technology. PeerJ. 2016;4:e2343.

4. Ellman MS, Schwartz ML. Online Learning Tools as Supplements for Basic and Clinical Science Education. J Med Educ Curric Dev. 2016;3.

5. Cavuoto Petrizzo M, Barilla-LaBarca ML, Lim YS, Jongco AM, Cassara M, Anglim J, Stern JNH. Utilization of high-fidelity simulation to address challenges with the basic science immunology education of preclinical medical students. BMC Med Educ. 2019;19:352.

6. Fincher RM, Wallach PM, Richardson WS. Basic science right, not basic science lite: medical education at a crossroad. J Gen Intern Med. 2009;24:1255-8.

7. Zhou T, Huang S, Cheng J, Xiao Y. The Distance Teaching Practice of Combined Mode of Massive Open Online Course Micro-Video for Interns in Emergency Department During the COVID-19 Epidemic Period. Telemed J E Health. 2020;26:584-8.

8. Dost S, Hossain A, Shehab M, Abdelwahed A, Al-Nusair L. Perceptions of medical students towards online teaching during the COVID-19 pandemic: a national cross-sectional survey of 2721 UK medical students. BMJ Open. 2020;10:e042378.

9. Luo Y, Zhou G, Li J, Xiao X. Study on MOOC scoring algorithm based on Chinese University MOOC learning behavior data. Heliyon. 2018;4:e00960.

10. Davies S, Lorello GR, Downey K, Friedman Z. Effective learning environments - the process of creating and maintaining an online continuing education tool. Adv Med Educ Pract. 2017;8:447-52.

11. Xing W, Ao L, Xiao H, Cheng L, Liang Y, Wang J. Nurses' Attitudes toward, and Needs for Online Learning: Differences between Rural and Urban Hospitals in Shanghai, East China. Int J Environ Res Public Health. 2018;15:1495.

12. Asiry MA. Dental students' perceptions of an online learning. Saudi Dent J. 2017;29:167-70.

13. Francis MK, Wormington SV, Hulleman C. The Costs of Online Learning: Examining Differences in Motivation and Academic Outcomes in Online and Face-to-Face Community College Developmental Mathematics Courses. Front Psychol. 2019;10:2054.

\section{Figures}



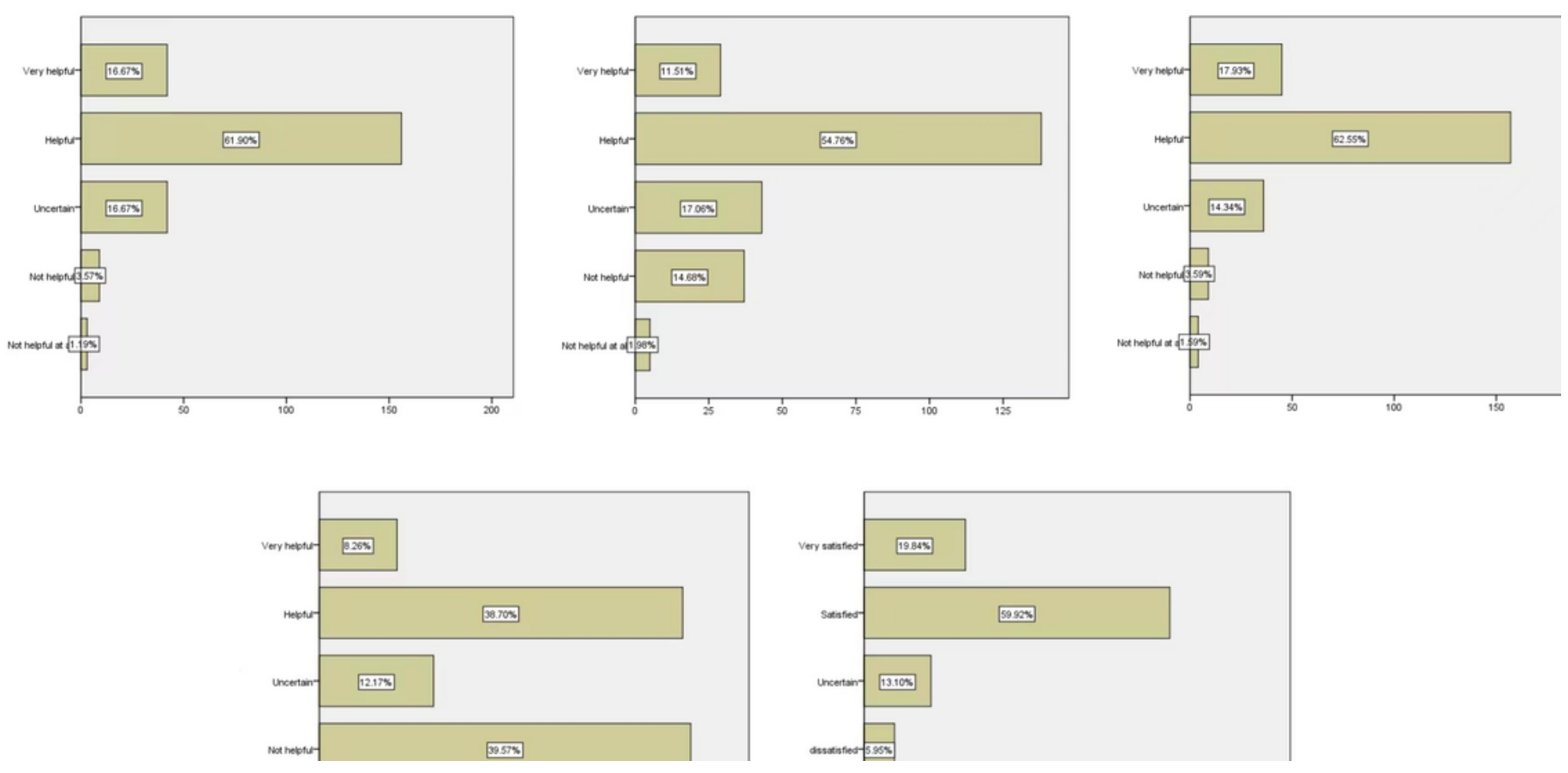

\section{Figure 1}

The evaluation of undergraduates on the online teaching. (a) Helpful of review knowledge; (b) Helpful of master knowledge; (c) Helpful of handle queries; (d) Helpful of efficient learning; (e) Satisfaction with online teaching

Unmomonnity tont of

X

\section{Figure 2}

The final examination scores of 2019, 2018 and 2017 students were analyzed by Kruskal-Wallis test and analyzed by variance. 